\title{
Postnatal screening and care for non- medical risk factors by preventive child healthcare in deprived and non-deprived neighbourhoods
}

\author{
M. R. C. van Minde ${ }^{1,2^{*}}$ (D, S. M. Hulst ${ }^{1}$, H. Raat ${ }^{2}$, E. A. P. Steegers ${ }^{1}$ and M. L. A. de Kroon ${ }^{1,2,3}$
}

\begin{abstract}
Background: Children born in families with non-medical risk factors, such as deprivation, have higher odds of preterm birth ( $<37$ weeks of gestation) or being born small for gestational age (birth weight $<10$ th percentile). In addition, growing up they are at risk for growth and developmental problems. Preventive Child Healthcare (PCHC) monitors growth and development of babies and children. Early identification of children at risk could result in early interventions to prevent growth and developmental problems in later life. Therefore, we aimed to assess current practices in postnatal risk screening and care for non-medical risk factors and the collaboration with other healthcare professionals, in both deprived and non-deprived neighbourhoods in the Netherlands.
\end{abstract}

Methods: Eight out of ten invited PCHC organisations, from different areas in the Netherlands, consented to participate in this study. A questionnaire was designed and digitally distributed to professionals working at these organisations, where 370 physicians and nurses were employed. Data was collected between June and September 2016. Descriptive statistics, chi square tests and t-tests were applied.

Results: Eighty-nine questionnaires were eligible for analyses. Twenty percent of the respondents were working in a deprived neighbourhood and $70.8 \%$ of the respondents were employed as nurse. Most of them performed screening for non-medical risk factors in at least $50 \%$ of their consultations. PCHC professionals working in deprived neighbourhoods encountered significantly more often families with non-medical risk factors and experienced significantly more communication problems than their colleagues working in nondeprived neighbourhoods. $48.2 \%$ of the respondents were satisfied with the current form of postnatal risk screening in their organisation, whereas $41.2 \%$ felt a need for a structured postnatal risk assessment. Intensified collaboration is preferred with district-teams, general practitioners and midwifes, concerning clients with non-medical risk factors.

Conclusion: This study shows that postnatal screening for non-medical risk factors is part of current PCHC practice, regardless the neighbourhood status they are deployed. PCHC professionals consider screening for non-medical risk factors as their responsibility. Consequently, they felt a need for a structured postnatal risk assessment and for an intensified collaboration with other healthcare professionals.

Keywords: Preventive child healthcare, Non-medical risk factors, Risk screening practices, Postnatal risk assessment, Vulnerable families, Deprived neighbourhoods

\footnotetext{
* Correspondence: m.vanminde@erasmusmc.nl

'Department of Obstetrics \& Gynaecology, Division of Obstetrics and

Prenatal Medicine, Erasmus University Medical Centre, Rotterdam, The

Netherlands

${ }^{2}$ Department of Public Health, Erasmus University Medical Centre, Rotterdam,

The Netherlands

Full list of author information is available at the end of the article
}

(c) The Author(s). 2018 Open Access This article is distributed under the terms of the Creative Commons Attribution 4.0 International License (http://creativecommons.org/licenses/by/4.0/), which permits unrestricted use, distribution, and reproduction in any medium, provided you give appropriate credit to the original author(s) and the source, provide a link to the Creative Commons license, and indicate if changes were made. The Creative Commons Public Domain Dedication waiver (http://creativecommons.org/publicdomain/zero/1.0/) applies to the data made available in this article, unless otherwise stated. 


\section{Background}

The developmental theory of health and disease identified the first 1000 days (from conception to the age of 2 years) as a critical and sensitive period for the development of a human being [1]. Initial vulnerability for future disease can be aggravated by growing up in an unfavourable socio-economic environment or by other non-medical risk factors, such as lack of social support or domestic violence, affecting a child's growth and development $[1,2]$. Parental lifestyle factors such as smoking, substance abuse (drugs and alcohol) and obesity are also considered as non-medical risk factors [3] and individually influence growth and development of children [4-7]. Medical risk factors such as preterm birth and being born small for gestational age (SGA) are independently associated with a high risk for growth and developmental problems in children [8-10]. Additionally, in deprived neighbourhoods these medical risk factors are more common [11]. Both medical and non-medical risk factors, the accumulation and the interaction of these risks explain the difference in perinatal and child health among deprived and non-deprived neighbourhoods [12-14].

In the Netherlands, Preventive Child Healthcare (PCHC) organisations are responsible for monitoring child growth and development and of the promotion of healthy lifestyles. PCHC is offered to all children, from birth until the age of 19 years by the Dutch government, free of charge. For children in the age of zero up to 4 years old, consultations comprise of growth and developmental measurements, regular visits to the national vaccination programme and parenting advice. These consultations have high attendance rates (> 95\%) [15].

To our knowledge, a structured postnatal risk assessment for growth and development, combining both medical and non-medical risk factors, does not yet exist for PCHC. However, for the early detection of developmental problems in toddlers, an instrument has been developed for the application in PCHC [16]. In obstetric care, an antenatal risk assessment has been developed and evaluated, assessing the risk of unfavourable birth outcomes in the first trimester of pregnancy [17].

Moreover, PCHC professional opinion on this subject has not been studied before. Studies on the views and needs of PCHC professionals are scarce. Häggman-Laitila et al. [18] described public health nurses views on the needs for special support of Finnish families, where the needs varied per region. Their findings correspond with the results of a qualitative study by Mundet-Tuduri et al. [19], who highlighted the different educational needs of public healthcare professionals, varying per region and organisation. Concerning the implementation of screening instruments, Garg et al. [20] highlighted the practical challenges of the use of recommended screening tools as part of developmental surveillance. They stressed on the need for further research regarding the most effective integrated models of care [20].

\section{Objective}

We aimed to assess current postnatal risk screening and care practices for non-medical risk factors, additional to medical risk factors, in PCHC. We hypothesized that the magnitude of screening and care practices in the postnatal period, could be affected by working in a deprived or non-deprived neighbourhood. Additionally, we assessed the needs of PCHC professionals and their collaboration with other healthcare providers.

\section{Methods \\ Study design}

This study concerns a cross-sectional descriptive survey. The survey was conducted among PCHC professionals (physicians and nurses) working at eight different $\mathrm{PCHC}$ organisations in urban and rural regions in the Netherlands. This study is part of the Healthy Pregnancy 4 All-2 (HP4All-2) program [21]. HP4All-2 aims to enforce and facilitate continuous care for families at risk after birth by focusing on antenatal and postnatal risk assessment in combination with tailored care pathways by maternity care, PCHC and interconception care [21].

\section{Setting and study population}

Every municipality in the Netherlands is responsible for coordinating their own PCHC services. Most municipalities organise $\mathrm{PCHC}$ within their Municipal Health Services, while some of them subcontract commercial healthcare organisations to carry out PCHC. Both types of $\mathrm{PCHC}$ organisations were included in order to reflect the current situation in the Netherlands. PCHC professionals in the Netherlands all comply with the same training conditions and they work according to the general requirements for $\mathrm{PCHC}$, imposed by the Dutch government [22]. The study population consisted of PCHC nurses and PCHC physicians employed at these organisations. Recent data indicate that there are 36 different PCHC organisations in the Netherlands, providing care for children from birth until 19 years of age (often professionals work for either the age group 0-4 years old or the age group 5-19 years old) [23]. With the assistance of professionals working at organisations within the HP4All-2 network [21], we invited 10 different organisations, in both urban and rural areas across the country, to participate in our survey. We addressed healthcare professionals who work with children from zero up to 4 years old, because this age interval includes the postnatal period. 


\section{Development of the questionnaire}

Data were collected using an electronic questionnaire, which was developed in analogy with the validated MIDI questionnaire, an instrument to measure determinants of innovations in healthcare [24]. Finally, the questionnaire contained 41 questions, which were either closed or open-ended. The questions were divided in four domains: (A) respondent characteristics, (B) current risk screening practices (C) handover of antenatal data, and (D) collaboration with other healthcare professionals. The questions which measured the knowledge of non-medical risk factors were based on recent literature and, if available, systematic reviews or meta-analyses [4-10, 14, 25-29]. Data concerning the deprivation status of a neighbourhood in which the PCHC professional was working during the study period, was defined according to the NIVEL coding. NIVEL, the institute for health services research in the Netherlands, publishes a quadrennial overview of deprived urban areas by zip code. Every 4 years, the NIVEL institute aggregates neighbourhood-level data on the number of inhabitants, the area density by address, the proportion of non-western inhabitants, average income of residents with an income and the number of residents with social security benefits. Hence, a standardised formula is used to calculate the so-called deprivation index. Based on this deprivation index, deprived neighbourhoods are designated [30, 31]. The questionnaire was piloted among three PCHC professionals to examine whether terms and definitions were clear and precise. For its design and distribution we used the online survey program, LimeSurvey
(Pro version, (c) 2003). A summary of the questionnaire is presented in Fig. 1. The full questionnaire can be made available upon request.

\section{Exclusion criteria}

Preliminary exclusion criteria for analysis were not being employed as a PCHC physician or nurse, and not working with the age-group zero up to 4 years old.

\section{Data collection}

Data were collected between May and August 2016. As soon as the PCHC organisations agreed to participate, they received an email containing the link to the electronic questionnaire in LimeSurvey. The management of the participating organisations distributed the link among their (selection of) employees and they were asked to send at least one reminder. Most PCHC organisations participated with their whole workforce, others decided to distribute the questionnaire among a selected group of employees, e.g. limited to one zip code area or neighbourhood. The managers themselves made the decision on how to distribute the questionnaire within their organisation.

\section{Data analyses}

Descriptive statistics were applied to quantitatively describe the main features of the data. Additionally, comparative statistics were used, i.e. the chi-squared test and the Fisher's exact test (if expected frequencies were not greater than five) to measure associations between two categorical variables. The unpaired $t$-test or Mann-Whitney $U$ test were applied to compare ordinal or interval variables
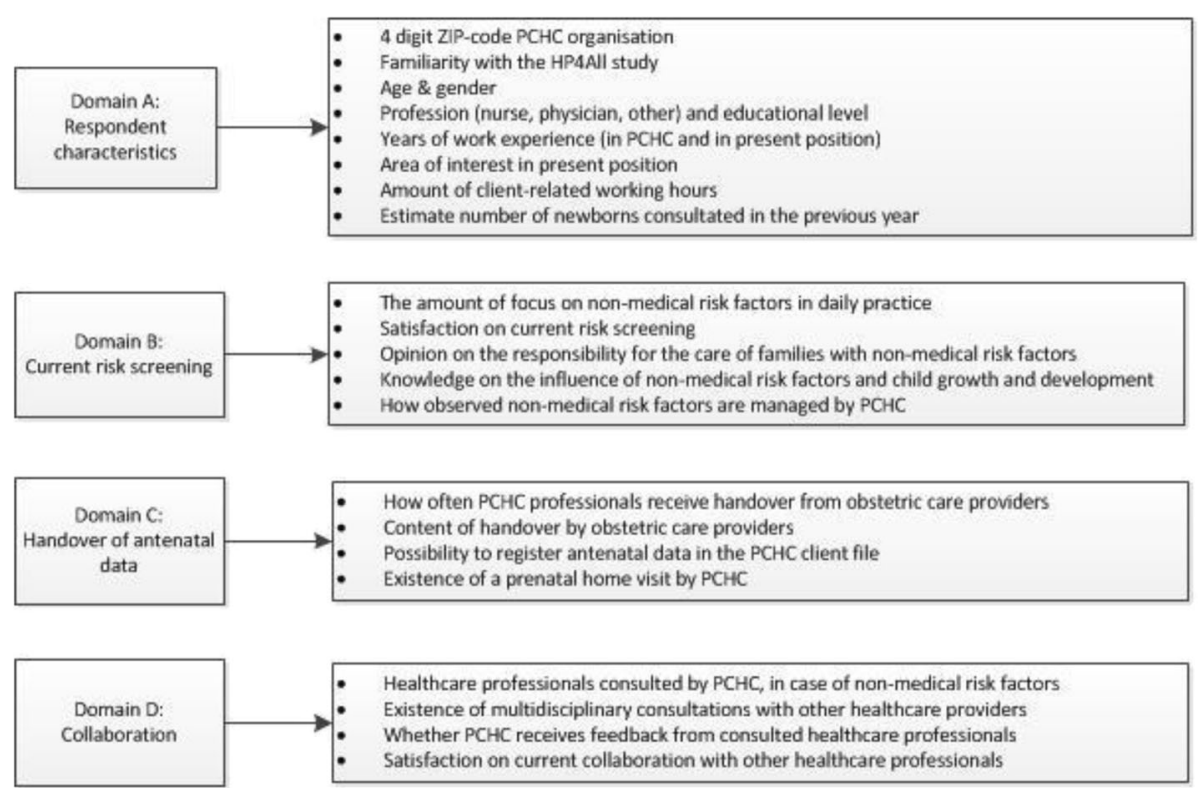

Fig. 1 Domains, constructs and items of the questionnaire 
between two (in-)dependent groups. All statistical analyses were performed using SPSS software (version 20.0). Statistical significance was defined as a $p$ value $<0.05$.

\section{Results}

Eight out of ten invited $\mathrm{PCHC}$ organisations agreed to participate. The eight participating organisations were nationally scattered, representing both urban and rural regions of the country. The response rate per organisation varied from $100 \%$, being the highest, to $15,6 \%$, being the lowest response rate; $100 \%$ reflecting an organisation which had chosen to distribute to questionnaire to the employees of one specific neighbourhood and 15,6\% reflecting an organisation which had sent the questionnaire to their whole workforce. Figure 2 represents the flowchart of excluded questionnaires. Eighty-nine questionnaires remained available for analyses.

Table 1 shows the respondents' characteristics. Twenty percent of the respondents were working in a deprived neighbourhood according to the NIVEL coding [30]. $70.8 \%$ of the respondents were nurses and $29.2 \%$ were physicians. Age and working experience did not differ between professionals working in deprived and non-deprived neighbourhoods. Professionals working in a deprived neighbourhood had, on average, less client related activities per week and a lower number of consulted new-borns a year, than those working in a non-deprived neighbourhood.

Table 2 shows that $36 \%$ of the respondents encountered vulnerable families a couple of times a month and $30.3 \%$ encountered these families a couple of times a week, in the previous year. Professionals working in

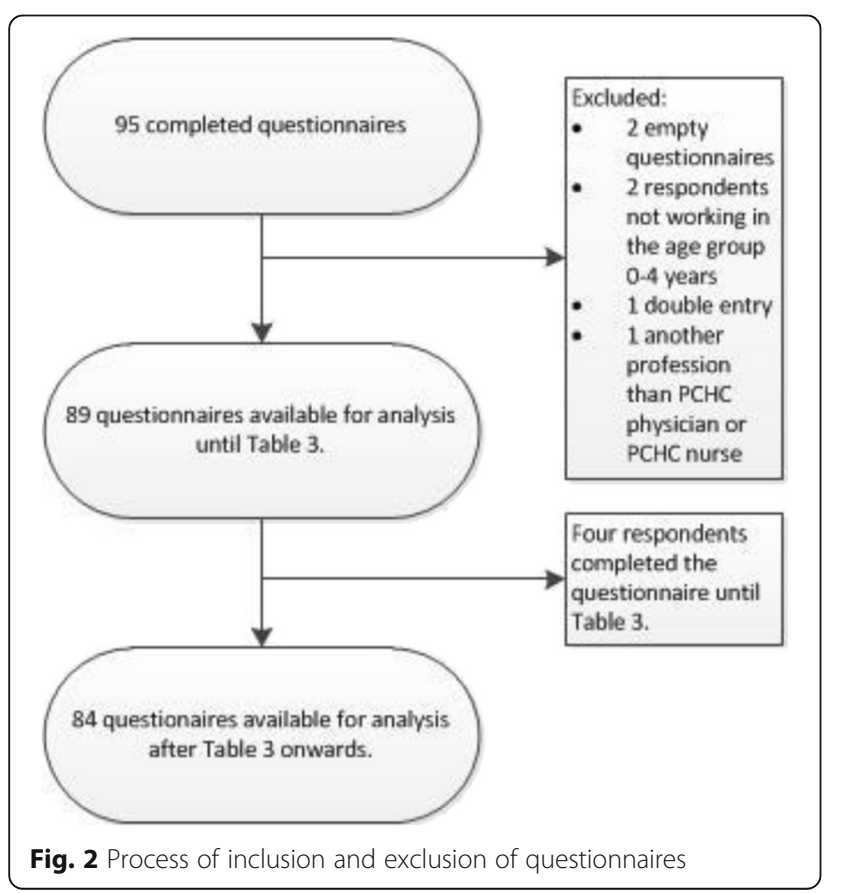

deprived neighbourhoods encountered vulnerable families significantly more often $(p$ value $=0.025)$. Most of the respondents, $47.2 \%$, experienced severe communication problems with clients several times a year, and $32.6 \%$ a couple of times a month. This percentage was significantly higher for professionals in deprived versus non-deprived neighbourhoods ( $p$ value $=0.001$ ). With respect to the availability of guidelines or protocols for postnatal screening, $83.1 \%$ of the professionals indicated that these were available or being developed. Nine percent indicated that protocols were not available in their organisation and $2.2 \%$ did not know. This result did not differ between professionals working in deprived and non-deprived neighbourhoods ( $p$ value $=0.781$ ).

To assess current knowledge on risk factors influencing a child's growth and development, respondents could indicate whether they thought a certain risk factor influences either growth or development of a young child. Table 3 shows the percentage of respondents who gave the correct answer, based on recent literature, which varied from 39.3 to $98.9 \%$. Professionals working in non-deprived neighbourhoods had significantly better knowledge of financial problems and child overweight/ obesity than those working in deprived neighbourhoods. However, for most questions no significant differences were found.

With regard to how many times in the previous year respondents performed screening on the prelisted non-medical risk factors, no significant difference was found in professionals working in deprived versus non-deprived neighbourhoods. Most of the respondents discussed smoking $(68,2 \%)$, drug use $(65,9 \%)$ and alcohol consumption $(61,2 \%)$ in every consultation. Maternal weight was discussed the least by PCHC professionals (21.2\% in none of the consultations). Domestic violence was not discussed often either; $11.2 \%$ of the professionals never discussed this topic during a consultation.

When encountering non-medical risk factors during a first consultation with a new-born baby, $12.2 \%$ did never offer an intervention, whereas $10 \%$ did always intervene. These interventions consisted of additional consultations by $\mathrm{PCHC}$ or referral to another healthcare professional. Most of the constraints for not offering an intervention were client related (82.4\%) (e.g. financial restrictions or the prolonged traveling time to a care facility), less were related to healthcare professional restrictions (too little time during consultations) or to the intervention itself (such as waiting lists).

Healthcare professionals most often consulted by $\mathrm{PCHC}$, in case of clients with non-medical risk factors, were social workers $(15.3 \%$ in more than $50 \%$ of the clients) and Youth Welfare Service specialists (14.1\% in more than $50 \%$ of the clients). Least consulted were gynaecologists and midwifes. No significant differences 
Table 1 Respondents' characteristics stratified by deprived and non-deprived neighbourhoods $(n=89)$

\begin{tabular}{|c|c|c|c|c|c|c|}
\hline \multirow[t]{2}{*}{ Neighbourhood status } & \multicolumn{3}{|c|}{ Deprived neighbourhood } & \multicolumn{3}{|c|}{ Non-deprived neighbourhood } \\
\hline & \multirow{3}{*}{$\begin{array}{l}\mathrm{n} \\
11 \\
n\end{array}$} & \multicolumn{2}{|l|}{ Percentage } & \multirow{3}{*}{$\begin{array}{l}\mathrm{n} \\
52 \\
\mathrm{n}\end{array}$} & \multirow{2}{*}{\multicolumn{2}{|c|}{$\frac{\text { Percentage }}{73 \%}$}} \\
\hline \multirow[t]{2}{*}{ Profession (\% nurses) } & & \multicolumn{2}{|l|}{$61 \%$} & & & \\
\hline & & Mean (SD) & Range & & Mean (SD) & Range \\
\hline Age (in years) & 18 & $46.9(10.1)$ & $22-60$ & 71 & $47.5(0.5)$ & $26-63$ \\
\hline Working experience PCHC (in years) & 18 & $16.2(9.1)$ & $1-28$ & 71 & $16.3(8.9)$ & $1-38$ \\
\hline Working experience in current position (in years) & 18 & $13.8(9.0)$ & $1-28$ & 71 & $14.4(7.7)$ & $1-35$ \\
\hline Client-related activities (in number of days per week) & 18 & $2.7(0.8)$ & $2-5$ & 71 & $3.1(0.7)$ & $1-4$ \\
\hline Consultations with new-borns (estimated number in the previous year) & 16 & $120.9(75.2)$ & $50-350$ & 68 & $132.7(87.0)$ & $40-450$ \\
\hline
\end{tabular}

were found between professionals working in deprived and non-deprived neighbourhoods.

Figure 3 represents the opinion of the respondents on current postnatal risk screening in their organisation, stratified by neighbourhood status. Most of the respondents (49.4\%) were (very) satisfied and $40 \%$ of the respondents had no opinion. When it comes to the need for a structured postnatal risk assessment, most of the respondents were in favour (50.6\%) of such an assessment and $48.2 \%$ had no opinion. This finding did not significantly differ between professionals working in deprived or and non-deprived neighbourhoods (Fig. 4), neither did it differ between physicians and nurses.

Regarding which healthcare professional should be the primary caregiver for families with non-medical risk factors (multiple answers were allowed), PCHC professionals favoured the general practitioner (62.2\%), social work (75.3), PCHC physicians (78.8\%), PCHC nurses (91.8\%) and the district teams (89.9\%), in which, in some municipalities, PCHC is a part of. In a district team, healthcare and social care professionals from a certain neighbourhood collaborate, in order to support clients close to home. In contrast, $82.4 \%$ of the respondents did not favour the gynaecologist or the paediatrician, and $74.1 \%$ did not favour the midwife as the primary caregiver. This opinion did not differ significantly between nurses and physicians or between professionals working in deprived and non-deprived neighbourhoods. (The full list of considered healthcare professionals can be found in Additional file 1: Table S1).
When it comes to the healthcare professional with whom the respondents would like to intensify collaboration, $67.1 \%$ mentioned district teams and $62.4 \%$ the general practitioner. In contrast, the majority did not feel the need to intensify collaboration with gynaecologists or the paediatrician (71.8 and $67.1 \%$, respectively). This opinion did not significantly differ between PCHC nurses and $\mathrm{PCHC}$ physicians, and neither between neighbourhoods. (The full list of considered healthcare professionals can be found in Additional file 1: Table S2) $18.8 \%$ of the $\mathrm{PCHC}$ professionals did indicate they received handover from midwifes for every client and 25.9\% received handover from maternity care for every client. For the other professions these percentages were lower. Details on smoking and substance abuse (drugs and alcohol) during pregnancy were most frequently missing in the handover, whereas almost all information can be registered in the $\mathrm{PCHC}$ client file.

\section{Discussion}

The aim of this survey was to identify current Dutch $\mathrm{PCHC}$ risk screening practices and care for non-medical risk factors, during the postnatal period. Additionally, we studied different views and needs of professionals working in deprived and non-deprived neighbourhoods, the content of handover and their collaboration with other healthcare professionals.

Our study shows that PCHC professionals encounter clients with non-medical risk factors quite often, especially those working in deprived neighbourhoods. The importance of screening for non-medical risk factors

Table 2 Current risk screening in PCHC according to PCHC physicians and nurses $(n=89)$

\begin{tabular}{|c|c|c|c|c|c|c|}
\hline & $\begin{array}{l}\text { Never } \\
\mathrm{n}(\%)\end{array}$ & $\begin{array}{l}\text { Couple of } \\
\text { times a year } \\
\mathrm{n}(\%)\end{array}$ & $\begin{array}{l}\text { Couple of } \\
\text { times per month } \\
\mathrm{n}(\%)\end{array}$ & $\begin{array}{l}\text { Couple of } \\
\text { times per week } \\
n(\%)\end{array}$ & $\begin{array}{l}\text { Every day } \\
\mathrm{n}(\%)\end{array}$ & $\begin{array}{l}\text { Multiple times } \\
\text { a day } \\
\text { n (\%) }\end{array}$ \\
\hline $\begin{array}{l}\text { Encountering families with non-medical } \\
\text { risk factors, in the previous year }\end{array}$ & $0(0)$ & $8(9)$ & 32 (36) & $27(30.3)$ & $13(14.6)$ & $9(10.1)$ \\
\hline $\begin{array}{l}\text { Severe communication problems with } \\
\text { families during consultations, } \\
\text { in the previous year }\end{array}$ & $3(3.4)$ & $42(47.2)$ & 29 (32.6) & $10(11.2)$ & $4(4.5)$ & $1(1.1)$ \\
\hline
\end{tabular}


Table 3 Knowledge of PCHC professionals on risk factors for growth and developmental problems $(n=89)$

\begin{tabular}{|c|c|c|c|c|c|c|c|c|c|c|}
\hline \multirow[t]{2}{*}{$\begin{array}{l}\text { Non-medical risk } \\
\text { factor }\end{array}$} & \multirow[t]{2}{*}{$\begin{array}{l}\text { Correct answer } \\
\text { [reference] }\end{array}$} & \multicolumn{4}{|c|}{$\begin{array}{l}\text { Number of correct answers on } \\
\text { the risk of overweight/ obesity }\end{array}$} & \multirow[t]{2}{*}{$\begin{array}{l}\text { Correct answer } \\
\text { [reference] }\end{array}$} & \multicolumn{4}{|c|}{$\begin{array}{l}\text { Number of correct answers on } \\
\text { the risk of developmental problems }\end{array}$} \\
\hline & & $\begin{array}{l}\text { Deprived } \\
(n=18)\end{array}$ & $\begin{array}{l}\text { Non-deprived } \\
(n=71)\end{array}$ & $p$ value & $\begin{array}{l}\text { Total } \\
n(\%)\end{array}$ & & $\begin{array}{l}\text { Deprived } \\
(n=18)\end{array}$ & $\begin{array}{l}\text { Non-deprived } \\
(n=71)\end{array}$ & $p$ value & $\begin{array}{l}\text { Total } \\
n(\%)\end{array}$ \\
\hline Parental smoking & $\begin{array}{l}\text { Yes } \\
{[37]}\end{array}$ & 8 & 27 & 0.406 & $35(39.3)$ & $\begin{array}{l}\text { Yes } \\
{[38,39]}\end{array}$ & 17 & 63 & 0.418 & $80(89.9)$ \\
\hline Parental drug use $\mathrm{e}^{\mathrm{a}}$ & $N A^{a}$ & $N A^{a}$ & $N A^{a}$ & $N A^{a}$ & $N A^{a}$ & $\begin{array}{l}\text { Yes } \\
{[26,27]}\end{array}$ & 18 & 69 & 0.635 & $87(97.8)$ \\
\hline Family income & $\begin{array}{l}\text { Yes } \\
{[40]}\end{array}$ & 17 & 68 & 0.602 & $85(95.5)$ & $\begin{array}{l}\text { Yes } \\
{[41]}\end{array}$ & 17 & 59 & 0.205 & $76(85.4)$ \\
\hline $\begin{array}{l}\text { Parental relationship } \\
\text { problems }^{\mathrm{a}}\end{array}$ & $N A^{a}$ & $N A^{a}$ & $N A^{a}$ & $N A^{a}$ & $N A^{a}$ & $\begin{array}{l}\text { Yes } \\
{[42]}\end{array}$ & 18 & 70 & 0.789 & $88(98.9)$ \\
\hline Domestic violence & $\begin{array}{l}\text { Yes } \\
{[43]}\end{array}$ & 14 & 43 & 0.138 & $57(64.0)$ & $\begin{array}{l}\text { Yes } \\
{[42,44]}\end{array}$ & 18 & 70 & 0.798 & $88(98.9)$ \\
\hline Maternal overweight & $\begin{array}{l}\text { Yes } \\
{[29]}\end{array}$ & 18 & 70 & 0.798 & 88 (98.9) & $\begin{array}{l}\text { Yes } \\
{[45]}\end{array}$ & 12 & 43 & 0.424 & $55(61.8)$ \\
\hline $\begin{array}{l}\text { Maternal alcohol } \\
\text { abuse }\end{array}$ & $\begin{array}{l}\text { No } \\
{[46]}\end{array}$ & 11 & 36 & 0.301 & $47(52.8)$ & $\begin{array}{l}\text { Yes } \\
{[6]}\end{array}$ & 18 & 65 & 0.246 & $83(93.3)$ \\
\hline Financial problems & $\begin{array}{l}\text { Yes } \\
{[47]}\end{array}$ & 17 & 51 & 0.035 & $68(76.4)$ & $\begin{array}{l}\text { Yes } \\
{[41]}\end{array}$ & 17 & 63 & 0.418 & $80(89.9)$ \\
\hline Lack of social support & $\begin{array}{l}\text { Yes } \\
{[48]}\end{array}$ & 18 & 59 & 0.054 & $77(86.5)$ & $\begin{array}{l}\text { Yes } \\
{[49]}\end{array}$ & 18 & 69 & 0.635 & $87(97.8)$ \\
\hline
\end{tabular}

${ }^{\mathrm{a} N A}$ : not applicable; in our literature search no articles were found which addressed this risk factor in association with growth problems

seems to be recognised by PCHC professionals: most respondents often screen for important non-medical risk factors and they consider the care for vulnerable families as their responsibility. This corresponds with the development of Dutch PCHC guidelines and protocols, e.g. on parenting support, psychosocial problems, nutrition and eating habits and prevention of overweight. Although many $\mathrm{PCHC}$ professionals were satisfied with the current risk screening practices within their own organisation, half of the professionals feels the need for a structured postnatal risk assessment. This result did not

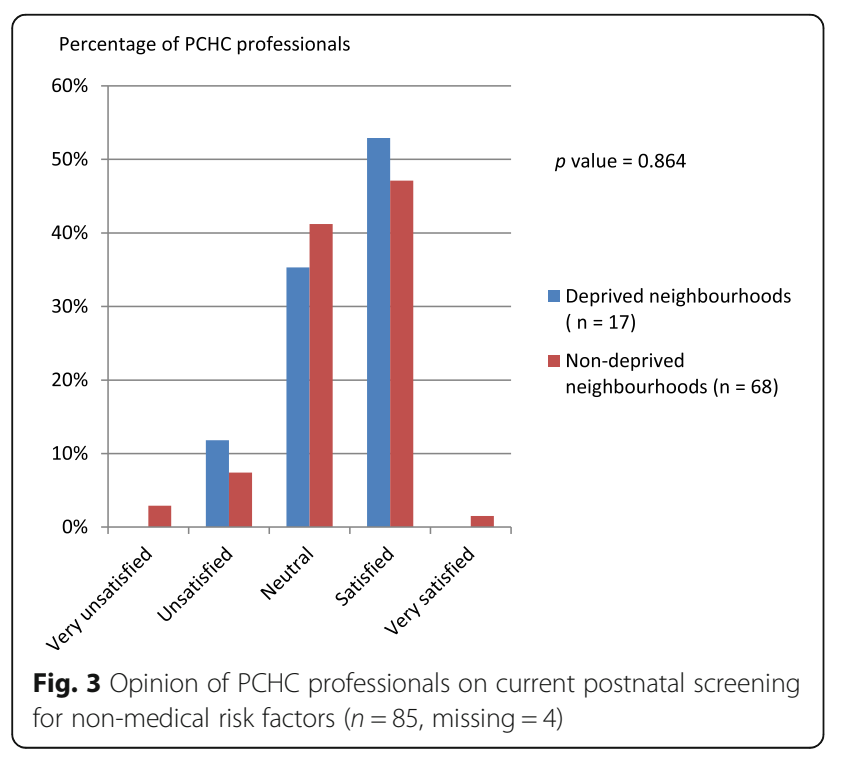

significantly differ between professionals working in deprived or non-deprived neighbourhoods or between physicians and nurses. Neither did this need differ between professionals working in an organisation where a protocol was available or not. An explanation for this result may be, that most $\mathrm{PCHC}$ professionals are aware of non-medical risk factors and are satisfied with current practice, but that they screen without an official, national guideline or instrument. Johansen et al. [32] showed that a structured assessment of motor development in infants was well received by $\mathrm{PCHC}$ nurses, as they valued that working with this instrument increased the quality of care provided.

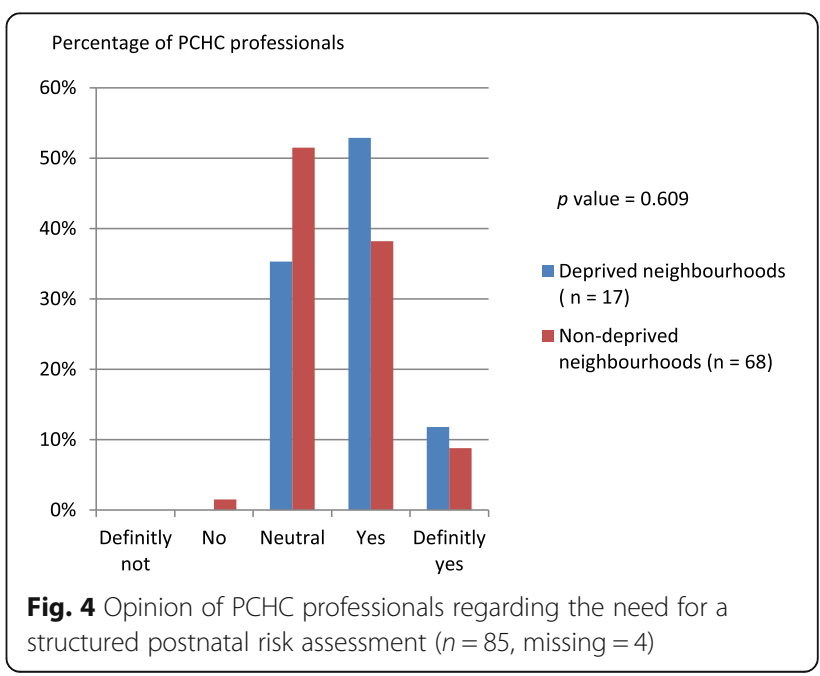


This study shows that $\mathrm{PCHC}$ professionals receive relatively few handovers from obstetric care professionals. Most handover is obtained from midwifes and maternity care, though not for every client. Moreover, essential information in the handover on prenatal and early postnatal smoking and substance abuse is often lacking, only one third of the professionals indicated that this information was 'always available' in handover documents.

Collaboration between healthcare professionals is advocated to improve patient outcomes [33] and enhances the quality of care given to individuals and groups in communities [34]. Poutianen et al. [35] showed that PCHC nurses' understanding of the role of family characteristics could be valuable in promoting multidisciplinary work in healthcare. Collaboration between Dutch PCHC and other healthcare professionals exists but still is quite rare. District team members were involved most often, which may be due to the fact that in some municipalities, $\mathrm{PCHC}$ is part of the district teams.

\section{Limitations and strengths}

A limitation of this study is that selection bias might have occurred, because of the non-random selection of participating $\mathrm{PCHC}$ organisations. Participating $\mathrm{PCHC}$ organisations might have been more eager to join the study because they were already more involved in postnatal non-medical risk screening. The response rate of the professionals within an organisation varied from $15.6 \%$ up to $100 \%$ between the $\mathrm{PCHC}$ organisations in this study. Nevertheless, we almost reached our target of completed questionnaires, having to rely on intermediates for the distribution of the questionnaire. The low response rate in some organisations could also be due to selection bias, as PCHC professionals who are more interested in the topic could be more willing to contribute to the survey. Another limitation of our study may be recall bias, which is a well-known restraint of survey studies. Our results show that most respondents can rely on protocols or local guidelines concerning risk screening. This might also have caused participants to respond with socially desirable answers due to their knowledge on certain risk factors, but not representing their current daily practice.

A strength of our study is that eight out of $36 \mathrm{PCHC}$ organisations in the Netherlands participated. These eight organisations are likely to be a good reflection of PCHC organisations nationally, covering different areas in the south, north, east and west of the country and both rural and urban municipalities. Moreover, the mean age in our sample (47.0 years; SD 10.5) and the physician/nurse ratio (0.41, drawn from Table 1$)$ are consistent with the results of Jambroes et al., who published an overview of the workforce of the Dutch PCHC services and who found a mean age of 48.0 (SD 10.2) years and a physician/nurse ratio of 0.48 [23]. This might indicate a good generalisability of our study, with a slight overrepresentation of nurses. However, since no significant differences between answers from physicians and nurses were found, this probably did not bias our results.

\section{Conclusion}

This study shows that postnatal screening for non-medical risk factors is part of current practice of Dutch PCHC professionals, regardless the kind of neighbourhood they are deployed. They consider screening for non-medical risk factors as their responsibility. This study, emphasizes the need felt for a structured, evidence-based, postnatal risk assessment including non-medical risk factors, as well as the need for an intensified collaboration with other healthcare professionals. In a world where family engaged care [36] is integrated in health care policy and practice, strengthening collaboration between healthcare professionals is necessary. A structured postnatal risk assessment focussing on child characteristics, as well as parental and environmental characteristics contributes to this multilevel approach.

\section{Implications of this study}

The management of PCHC organisations should invest in strengthening collaboration with other healthcare providers in a neighbourhood or municipality. Inter-professional collaboration across organisational boundaries is of utmost importance, especially for vulnerable families. Family engaged care and structured risk assessment for growth and developmental problems should become general practice in PCHC.

\section{Additional file}

Additional file 1 Table S1. Respondents' opinion on which healthcare professional should care for families with non-medical risks $(n=85)$. List of healthcare professionals considered, to care for families with nonmedical risk factors and PCHC professional opinion on who should be responsible to care for these families. Table S2. Respondents' opinion on with which healthcare professional collaboration should be intensified ( $n$ $=85$ ). List of healthcare professionals considered, with whom PCHC professionals could collaborate with and their opinion with which healthcare professional collaboration should be intensified. (DOCX 14 kb)

\section{Abbreviations}

NIVEL: Institute for health services research in the Netherlands; PCHC: Child preventive healthcare; SGA: Small for gestational age

Acknowledgements

We would like to thank all participating Preventive Child Healthcare organisations, without their participation this study would not have been possible. 


\section{Funding}

This study was part of the HP4All-2 program. This program has been funded by the Dutch government, Ministry of Welfare and Sports (VWS), grant 323911

\section{Availability of data and materials}

The data that support the findings of this study are available from the PCHC organisations (names were anonymised) participating in this study, but restrictions apply to the availability of these data, which were used under license for the current study, and thus are not publicly available. Data are however available from the authors upon reasonable request and with permission of the participating PCHC organisations.

\section{Authors' contributions}

ES conceived the HP4All and HP4All-2 program, MM and MK were responsible for the study design. MM has drafted the first version of the manuscript. ES, HR and SH participated in the design of the study. MK supervises the study. All authors have contributed to the final version of the manuscript and have given approval of the version to be published. All authors agreed to be accountable for all aspects of the work in ensuring that questions related to the accuracy or integrity of any part of the work are appropriately and resolved.

\section{Ethics approval and consent to participate}

This survey has been part of a study of the Healthy Pregnancy 4 All-2 (HP4All-2) program, which has been approved by the Medical Ethics Committee of the Erasmus Medical Centre (MEC-2015-697). Consent to participate was not applicable to this study.

\section{Competing interests}

The authors declare that they have no competing interests.

\section{Publisher's Note}

Springer Nature remains neutral with regard to jurisdictional claims in published maps and institutional affiliations.

\section{Author details \\ ${ }^{1}$ Department of Obstetrics \& Gynaecology, Division of Obstetrics and Prenatal Medicine, Erasmus University Medical Centre, Rotterdam, The Netherlands. ${ }^{2}$ Department of Public Health, Erasmus University Medical Centre, Rotterdam, The Netherlands. ${ }^{3}$ Department of Health Sciences, University Medical Centre Groningen, Groningen, The Netherlands.}

\section{Received: 31 January 2018 Accepted: 28 May 2018} Published online: 08 June 2018

\section{References}

1. Wallack L, Thornburg K. Developmental origins, epigenetics, and equity: moving upstream. Matern Child Health J. 2016;20(5):935-40.

2. Furumoto-Dawson A, Gehlert S, Sohmer D, Olopade O, Sacks T. Early-life conditions and mechanisms of population health vulnerabilities. Health Aff (Millwood). 2007;26(5):1238-48.

3. RG Wilkinson MM. Social determinants of health: the solid facts, second edition: World Health Organisation; 2003.

4. Ino T. Maternal smoking during pregnancy and offspring obesity: metaanalysis. Pediatr Int. 2010;52(1):94-9.

5. de Hoog ML, van Eijsden M, Stronks K, Gemke RJ, Vrijkotte TG. Overweight at age two years in a multi-ethnic cohort ( $A B C D$ study): the role of prenatal factors, birth outcomes and postnatal factors. BMC Public Health. 2011;11:611.

6. Knudsen AK, Skogen JC, Ystrom E, Sivertsen B, Tell GS, Torgersen L. Maternal pre-pregnancy risk drinking and toddler behavior problems: the Norwegian mother and child cohort study. Eur Child Adolesc Psychiatry. 2014:23(10):901-11

7. Zwicker JG, Yoon SW, Mackay M, Petrie-Thomas J, Rogers M, Synnes AR. Perinatal and neonatal predictors of developmental coordination disorder in very low birthweight children. Arch Dis Child. 2013:98(2):118-22.

8. Walden RV, Taylor SC, Hansen NI, Poole WK, Stoll BJ, Abuelo D, Vohr BR, National Institute of Child H, Human Development Neonatal Research N. Major congenital anomalies place extremely low birth weight infants at higher risk for poor growth and developmental outcomes. Pediatrics. 2007; 120(6):e1512-9.
9. Kerstjens JM, de Winter AF, Sollie KM, Bocca-Tjeertes IF, Potijk MR, Reijneveld SA, Bos AF. Maternal and pregnancy-related factors associated with developmental delay in moderately preterm-born children. Obstet Gynecol. 2013;121(4):727-33.

10. Delobel-Ayoub M, Kaminski M, Marret S, Burguet A, Marchand L, N'Guyen S, Matis J, Thiriez G, Fresson J, Arnaud C, et al. Behavioral outcome at 3 years of age in very preterm infants: the EPIPAGE study. Pediatrics. 2006;117(6): 1996-2005.

11. Denktas S, Poeran J, van Voorst SF, Vos AA, de Jong-Potjer LC, Waelput AJ, Birnie E, Bonsel GJ, Steegers EA. Design and outline of the healthy pregnancy 4 all study. BMC Pregnancy Childbirth. 2014;14:253.

12. Kerstjens JM, de Winter AF, Bocca-Tjeertes IF, Bos AF, Reijneveld SA. Risk of developmental delay increases exponentially as gestational age of preterm infants decreases: a cohort study at age 4 years. Dev Med Child Neurol. 2012:54(12):1096-101.

13. Timmermans S, Bonsel GJ, Steegers-Theunissen RP, Mackenbach JP, Steyerberg EW, Raat H, Verbrugh HA, Tiemeier HW, Hofman A, Birnie E, et al. Individual accumulation of heterogeneous risks explains perinatal inequalities within deprived neighbourhoods. Eur J Epidemiol. 2011;26(2): 165-80.

14. Bradley RH, Corwyn RF. Socioeconomic status and child development. Annu Rev Psychol. 2002;53:371-99.

15. Dunnink G L-SW: Activiteiten Basistakenpakket Jeugdgezondheidszorg 0-19 jaar per Contactmoment. 2008.

16. Staal II, Hermanns JM, Schrijvers AJ, van Stel HF. Risk assessment of parents' concerns at 18 months in preventive child health care predicted child abuse and neglect. Child Abuse Negl. 2013;37(7):475-84.

17. Vos AA, van Veen MJ, Birnie E, Denktas S, Steegers EA, Bonsel GJ. An instrument for broadened risk assessment in antenatal health care including non-medical issues. Int J Integr Care. 2015;15:e002.

18. Haggman-Laitila A, Euramaa Kl. Finnish families' need for special support as evaluated by public health nurses working in maternity and child welfare clinics. Public Health Nurs. 2003;20(4):328-38.

19. Mundet-Tuduri X, Crespo R, Fernandez-Coll ML, Saumell M, Millan-Mata F, Cardona A, Codern-Bove N. Expectations and perceptions of primary healthcare professionals regarding their own continuous education in Catalonia (Spain): a qualitative study. BMC Med Educ. 2017;17(1):212.

20. Garg P, Ha MT, Eastwood J, Harvey S, Woolfenden S, Murphy E, Dissanayake C, Williams K, Jalaludin B, McKenzie A, et al. Health professional perceptions regarding screening tools for developmental surveillance for children in a multicultural part of Sydney, Australia. BMC Fam Pract. 2018;19(1):42.

21. Waelput AJ. Geographical differences in perinatal health and child welfare in the Netherlands: rationale for the healthy pregnancy 4 all-2 program. BMC Pregnancy Childbirth. 2017;17:254

22. Staatssecretaris Ministerie WWS. Besluit van 5 november 2014, houdende aanpassing van het Besluit publieke gezondheid vanwege een gewijzigd basistakenpakket jeugdgezondheidszorg. Staatsblad van het Koninkrijk der Nederlanden. 2014;449

23. Jambroes M, Lamkaddem M, Stronks K, Essink-Bot ML. Enumerating the preventive youth health care workforce: size, composition and regional variation in the Netherlands. Health Policy. 2015:119(12):1557-64.

24. Fleuren MAH, Paulussen TGWM, Van Dommelen P, Van Buuren S. Towards a measurement instrument for determinants of innovations. Int J Qual Health Care. 2014;26(5):501-10.

25. Radford L, Corral S, Bradley C, Fisher HL. The prevalence and impact of child maltreatment and other types of victimization in the UK: findings from a population survey of caregivers, children and young people and young adults. Child Abuse Negl. 2013;37(10):801-13.

26. Lewis BA, Minnes S, Short EJ, Weishampel P, Satayathum S, Min MO, Nelson $\mathrm{S}$, Singer LT. The effects of prenatal cocaine on language development at 10 years of age. Neurotoxicol Teratol. 2011;33(1):17-24.

27. El Marroun $H$, Hudziak JJ, Tiemeier $H$, Creemers $H$, Steegers EA, Jaddoe WW, Hofman A, Verhulst FC, van den Brink W, Huizink AC. Intrauterine cannabis exposure leads to more aggressive behavior and attention problems in 18-month-old girls. Drug Alcohol Depend. 2011;118(2-3): 470-4.

28. El Marroun $H$, White TJ, van der Knaap NJ, Homberg JR, Fernandez G, Schoemaker NK, Jaddoe WW, Hofman A, Verhulst FC, Hudziak JJ, et al. Prenatal exposure to selective serotonin reuptake inhibitors and social responsiveness symptoms of autism: population-based study of young children. Br J Psychiatry. 2014;205(2):95-102. 
29. Yu Z, Han S, Zhu J, Sun X, Ji C, Guo X. Pre-pregnancy body mass index in relation to infant birth weight and offspring overweight/obesity: a systematic review and meta-analysis. PLoS One. 2013;8(4):e61627.

30. Reijneveld SA, Verheij RA, de Bakker DH. The impact of area deprivation on differences in health: does the choice of the geographical classification matter? J Epidemiol Community Health. 2000;54(4):306-13.

31. van Vuuren $C L$, Reijneveld SA, van der Wal MF, Verhoeff AP. Neighborhood socioeconomic deprivation characteristics in child (0-18 years) health studies: a review. Health Place. 2014;29:34-42.

32. Johansen K, Lucas S, Bokstrom P, Persson K, Sonnander K, Magnusson M, Sarkadi A. Now I use words like asymmetry and unstable': nurses' experiences in using a standardized assessment for motor performance within routine child health care. J Eval Clin Pract. 2016;22(2):227-34.

33. Nembhard IM, Tucker AL, Horbar JD, Carpenter JH. Improving patient outcomes: the effects of staff participation and collaboration in healthcare delivery: division of research: Harvard Business School; 2007.

34. Fewster-Thuente L, Velsor-Friedrich B. Interdisciplinary collaboration for healthcare professionals. Nurs Adm Q. 2008;32(1):40-8.

35. Poutiainen $\mathrm{H}$, Hakulinen-Viitanen $\mathrm{T}$, Laatikainen T. Associations between family characteristics and public health nurses' concerns at children's health examinations. Scand J Caring Sci. 2014;28(2):225-34.

36. Wieczorek CC, Nowak P, Frampton SB, Pelikan JM. Strengthening patient and family engagement in healthcare - the new haven recommendations. Patient Educ Couns. 2018;

37. Oken E, Levitan EB, Gillman MW. Maternal smoking during pregnancy and child overweight: systematic review and meta-analysis. Int J Obes. 2008; 32(2):201-10.

38. Alvik A. Variables predicting low infant developmental scores: maternal age above 30 years is a main predictor. Scand J Public Health. 2014;42(2):113-9.

39. Roza SJ, Verhulst FC, Jaddoe WW, Steegers EA, Mackenbach JP, Hofman A, Tiemeier H. Maternal smoking during pregnancy and child behaviour problems: the generation R study. Int J Epidemiol. 2009;38(3):680-9.

40. Demment MM, Haas JD, Olson CM. Changes in family income status and the development of overweight and obesity from 2 to 15 years: a longitudinal study. BMC Public Health. 2014;14:417.

41. Gershoff ET, Aber JL, Raver CC, Lennon MC. Income is not enough: incorporating material hardship into models of income associations with parenting and child development. Child Dev. 2007;78(1):70-95.

42. Gilbert AL, Bauer NS, Carroll AE, Downs SM. Child exposure to parental violence and psychological distress associated with delayed milestones. Pediatrics. 2013;132(6):e1577-83.

43. Gooding HC, Milliren C, Austin SB, Sheridan MA, McLaughlin KA. Exposure to violence in childhood is associated with higher body mass index in adolescence. Child Abuse Negl. 2015;50:151-8.

44. Gilbert R, Widom CS, Browne K, Fergusson D, Webb E, Janson S. Burden and consequences of child maltreatment in high-income countries. Lancet. 2009;373(9657):68-81.

45. Jo H, Schieve LA, Sharma AJ, Hinkle SN, Li R, Lind JN. Maternal prepregnancy body mass index and child psychosocial development at 6 years of age. Pediatrics. 2015;135(5):e1 198-209.

46. Mourtakos SP, Tambalis KD, Panagiotakos DB, Antonogeorgos G, Arnaoutis G, Karteroliotis K, Sidossis LS. Maternal lifestyle characteristics during pregnancy, and the risk of obesity in the offspring: a study of 5,125 children BMC Pregnancy Childbirth. 2015;15:66.

47. Weden MM, Brownell P, Rendall MS. Prenatal, perinatal, early life, and sociodemographic factors underlying racial differences in the likelihood of high body mass index in early childhood. Am J Public Health. 2012;102(11): 2057-67.

48. Shin HS, Valente TW, Riggs NR, Huh J, Spruijt-Metz D, Chou CP, Ann Pentz $\mathrm{M}$. The interaction of social networks and child obesity prevention program effects: the pathways trial. Obesity (Silver Spring). 2014:22(6):1520-6.

49. Crockenberg SB: Infant irritability, mother responsiveness, and social support influences on the security of infant-mother attachment. Child Dev 1981, 52(3, (september 1981)):857-865.

\section{Ready to submit your research? Choose BMC and benefit from:}

- fast, convenient online submission

- thorough peer review by experienced researchers in your field

- rapid publication on acceptance

- support for research data, including large and complex data types

- gold Open Access which fosters wider collaboration and increased citations

- maximum visibility for your research: over $100 \mathrm{M}$ website views per year

At BMC, research is always in progress.

Learn more biomedcentral.com/submissions 